\section{Papillary Microcarcinomas of the Thyroid: Letter Reply}

\section{TO THE EDITORS:}

We would like to thank Drs. Agarval et al. for their valuable comments regarding our recent study of papillary microcarcinomas of the thyroid. ${ }^{1} \mathrm{We}$ are happy to provide here additional details to clarify the points outlined in their letter.

The palpable node metastases in our patients were exclusively lateral. Regarding the question of both surgical and radioactive iodine (RAI) treatments of the patients enrolled in our study, the retrospective nature of the study, as well as the long period of time since treatment, had to be considered. Previously, total thyroidectomy, including lymphadenectomy and RAI ablation, was the standard procedure for patients with papillary carcinomas of the thyroid (PTC), regardless of tumor size and mode of detection. Later, as more data on PMCs became available, therapy in incidentally detected PMCs was individualized, taking all available clinical and histopathological data into consideration, and treatment options were also discussed with the patients.

In case 2 (Table 3 ), the patient underwent excision of a palpable lateral cervical node in another hospital. Pathological examination revealed PTC metastases. Afterwards, the patient was referred to our hospital, where a total thyroidectomy and a resection of the central cervical compartment were performed. Since no lymph nodes were detected on histopathological examination, we decided to assign this case to the group of patients with no nodes dissected. Although inadequate histopathological sampling of the central compartment cannot be ruled out, it should be kept in mind that the epiphenomenon of discontinuous node metastases sparing the central compartment is not rare in thyroid carcinomas. Skip metastases have been reported in $19.7 \%$ of papillary carcinomas and in $5.5 \%$ of PMCs. ${ }^{2,3}$ To better characterize multifocal PMCs, the total tumor size was recorded as the size of the largest tumor as well as the sum of the diameters of all tumor foci detected.

Case 3 (Table 3 ) displayed three different foci measuring $5.5,3.2$, and $2.0 \mathrm{~mm}$, resulting in a total tumor size of $10.7 \mathrm{~mm}$. Interestingly, total tumor size in our study did not differ between the incidental and the nonincidental PMC groups, as shown in Table 2. ${ }^{1}$

Extended hemithyroidectomy is composed of hemithyroidectomy, isthmusectomy, and resection of the medial portion of the lower pole of the contralateral lobe, as described by Hassanain and Weixler. ${ }^{4}$ Please note that the term "extended thyroidectomy" did not appear in our text.

\section{Nikolaus Neuhold, MD}

Kaiserin Elisabethspital der Gemeinde Wien - Pathology and Bacteriology, Vienna, Austria

e-mail: nikolaus.neuhold@wienkav.at

Published Online: 28 June 2011

(C) Society of Surgical Oncology 2011

\section{REFERENCES}

1. Neuhold N, Schultheis A, Hermann M, Krotla G, Koperek O, Birner P. Incidental papillary microcarcinoma of the thyroidfurther evidence of a very low malignant potential: a retrospective clinicopathological study with up to 30 years of follow-up. Ann Surg Oncol. 2011;23 [Epub ahead of print].

2. Machens A, Holzhausen HJ, Dralle H. Skip metastases in thyroid cancer: leaping the central lymph node compartment. Arch Surg. 2004;139:43-5.

3. Wada N, Duh QY, Sugino K, Iwasaki H, Kameyama K, Mimura T et al. Lymph node metastasis from 259 papillary thyroid microcarcinomas: frequency, pattern of occurrence and recurrence, and optimal strategy for neck dissection. Ann Surg. 2003;237(3): 399-407.

4. Hassanain M, Weixler M. Conservative management of well differentiated thyroid cancer. Can J Surg. 2010; 53(2):109-18. 